\title{
Synovitis in Psoriatic Arthritis: Immunohistochemistry, Comparisons With Rheumatoid Arthritis, and Effects of Therapy
}

\author{
Arno W. R. van Kuijk • Paul P. Tak
}

Published online: 19 April 2011

(C) The Author(s) 2011. This article is published with open access at SpringerLink.com

\begin{abstract}
Psoriatic arthritis (PsA) is a chronic inflammatory arthropathy associated with psoriasis that affects the peripheral joints, spine, and entheses. Most patients with PsA present with peripheral synovitis of the oligoarticular or polyarticular subtype. As one of the targets of this disease, studies on the synovium may provide insight into the mechanisms involved in this condition. Key findings from the available studies comparing synovial tissue of PsA and rheumatoid arthritis patients are discussed in this review. Also, changes in the synovial infiltrate, expression of proinflammatory cytokines and adhesion molecules, and vascularity in synovial tissue after treatment with various medications are addressed. Finally, a model for proof-of-principle study design using serial synovial biopsies is described, which could be used to predict clinical (in)efficacy in early clinical trial design in PsA.
\end{abstract}

Keywords Psoriatic arthritis · Synovium .

Immunohistochemistry - Synovitis · Rheumatoid arthritis ·

Therapy $\cdot$ Treatment

\section{Introduction}

Psoriatic arthritis (PsA) is a chronic inflammatory arthropathy of unknown etiology that is associated with psoriasis. It can

\footnotetext{
A. W. R. van Kuijk

Department of Rheumatology, Jan van Breemen Institute, Amsterdam, The Netherlands

e-mail: a.w.vankuijk@amc.uva.nl

A. W. R. van Kuijk $\cdot$ P. P. Tak $(\square)$

Division of Clinical Immunology and Rheumatology, Academic Medical Center/University of Amsterdam,

Room F4-105, P.O. Box 22700, 1100 DE Amsterdam,

The Netherlands

e-mail: p.p.tak@amc.uva.nl
}

affect the peripheral joints, spine, and entheses. Belonging to the spondyloarthritis ( $\mathrm{SpA}$ ) family, PsA is distinguished from rheumatoid arthritis (RA), the most common inflammatory arthropathy, by infrequent seropositivity for rheumatoid factor and anti-citrullinated peptide antibodies, as well as the presence of distinctive clinical features. These features include the involvement of the distal interphalangeal (DIP) joints; an asymmetric distribution of the inflamed joints; the presence of dactylitis (inflammation of an entire digit [finger or toe]), enthesitis, sacroiliitis, or spinal involvement; and, of course, psoriasis. Radiological changes in PsA can present as erosive lesions or osteolysis but also as periarticular new bone formation. Joint destruction is often progressive, with almost $50 \%$ of PsA patients from an early arthritis clinic showing radiological damage 2 years after first presentation [1], and the the degree of radiological damage in PsA is comparable to RA [2].

More than 35 years ago, Moll and Wright [3] described a large case series of patients with PsA on which they based a subdivision into five clinical phenotypes: polyarthritis, asymmetrical oligoarthritis, spondylitis, predominant DIP arthritis, and arthritis mutilans. This clinical heterogeneity and the difficulty classifying patients with PsA correctly has been a major concern over the years and may have hampered our pathophysiologic understanding of the disease. Most patients of the original cohort of Moll and Wright [3] were classified in the oligoarticular subgroup (70\%), and a minority in the other subgroups. In later cohorts, polyarticular PsA was usually the largest subgroup, at about $60 \%$ of the patients, as was put forward by Helliwell and Taylor [4]. The reasons for this discrepancy are not completely clear, but some have argued that these later cohorts may have included patients with seronegative RA with coincident psoriasis [4]. Moreover, the disease pattern in an individual patient can change over time as a result of evolution of the disease or treatment [5]. Recently, data from a large cohort were prospectively 
collected in the CASPAR (Classification Criteria for Psoriatic Arthritis) study (588 PsA patients, 525 controls with other inflammatory diseases, $70 \%$ of whom had RA) with the aim of constructing new classification criteria from patient-derived data [6]. Interestingly, when the collected data from this large cohort were investigated, it turned out that the patients with polyarticular PsA resembled those with oligoarticular PsA in several ways, much more so than they resembled patients with RA [7]. Thus, misclassification of seronegative RA as polyarticular PsA does not seem to be a major problem.

It has been hypothesized by some authors that PsA is mainly an entheseal disease [8]. Anatomically linking mechanical stress (entheses) to immunologically active tissue (synovium), the concept of the synovioenthesial complex (SEC) supports this hypothesis $[9,10 \bullet, 11 \bullet]$. Imaging studies have suggested that tendon and ligament insertion points to bone (entheses) are commonly subject to microdamage. Although the normal enthesis is avascular in its fibrocartilaginous region, microdamage to the entheses is associated with local cytokine release, tissue repair responses, and vessel ingrowth, which may evolve into subsequent inflammation. It also has been suggested that adjuvant molecules derived from bacteria may be preferentially deposited at the site of the SEC; hence, microdamage and propensity for bacterial molecule deposition in the context of certain genetic factors may lead to the characteristic inflammatory changes seen at the entheses in SpA, including PsA [11•]. Furthermore, because the nail is functionally integrated with the SEC associated with the DIP joints, this model provides a rationale for the combination of DIP arthritis and nail involvement that is often observed in PsA patients [9].

Whereas this model may provide a good explanation for entheseal-related inflammation and arthritis (eg, as observed in the DIP joints), it does not where there is no close relationship between the inflamed joints and enthesis or skin. As reported above, most patients with PsA in the major cohorts seem to have oligoarticular or polyarticular peripheral synovitis. Because the synovium is a primary site of inflammation in this disease, there has been increasing interest in studies of the synovial tissue from patients with RA or PsA. In addition to the use of synovial biopsies for diagnostic purposes $[12,13]$ and pathogenetic studies [14, 15], serial synovial biopsies could be used to evaluate the effects of treatments $[16 \bullet, 17]$. This approach may have merit in screening for potential efficacy during early drug development.

\section{Immunohistochemistry of Synovial Tissue in Psoriatic Arthritis Compared With Rheumatoid Arthritis}

Several studies have characterized the synovium in PsA compared with RA [15, 18-25], with variable results. In general, it is good to realize that there are large differences in synovial infiltrate and expression of proteins on an individual patient level, so all findings reported are on the group level. Confounding factors, such as differences in the use of antirheumatic drugs between both groups and the selection of patients, may have influenced the results of some studies. Also, that synovial tissue was collected in different ways (eg, arthroscopic or needle biopsies vs tissue obtained during joint replacement surgery) may account for some of the observed differences.

It has been suggested by several studies that the PsA synovium is characterized by less pronounced lining layer hyperplasia and fewer monocytes/macrophages than are seen in RA $[18,23]$. One group found fewer T and B cells in SpA synovium [22], while others reported fewer T cells in PsA synovial tissue in comparison with RA [15, 23, 25]. This is remarkable because psoriasis and PsA are thought of as Tcell-driven conditions. The lower number of T cells in PsA synovium does not mean, however, that these cells are not important in the pathogenesis, as a subset of specific $\mathrm{T}$ cells may be sufficient to promote the inflammatory process, and regulatory $\mathrm{T}$ cells may have anti-inflammatory effects. As a matter of fact, $\mathrm{T}$ cells are likely to be involved in the pathogenesis of psoriasis and PsA [26]. The infiltrate in lesional psoriasis skin mainly consists of activated $\mathrm{T}$ cells. In the synovial infiltrate, $\mathrm{T}$ cells are present among other cell types, and oligoclonal T-cell expansions have been demonstrated in both skin and synovium [27], suggesting that an antigen-driven T-cell response could be promoting ongoing inflammation. For T-cell migration to the skin, the chemokine receptor CCR4 is necessary. Interestingly, the ligand for CCR4, macrophage-derived chemokine (MDC, also known as CCL22) was recently demonstrated within the synovial membrane and in high concentrations in the synovial fluid of RA and PsA patients [28]. The presence of MDC facilitates migration of CCR4-expressing memory cells into the inflamed joint, supporting the notion that MDC/CCR4 could play a role in attracting skin-specific memory $\mathrm{T}$ cells to the synovial compartment. The role of $\mathrm{T}$ cells is further underlined in psoriasis and PsA by the beneficial effect of therapies against $T$ cells, such as cyclosporin $A$ and alefacept [29-31]. Interestingly, a recently published paper on the effects of abatacept, a selective inhibitor of T-cell activation via competitive binding to $\mathrm{CD} 80$ or $\mathrm{CD} 86$, in PsA demonstrated the efficacy of using abatacept on joints, but a less strong effect on skin [32]. Interleukin (IL)-17producing T-helper cells (Th17 cells) are a recently recognized effector T-lymphocyte population playing a role in chronic inflammatory conditions. IL-23 is highly expressed in psoriatic plaques [33], and this cytokine is responsible for stimulating Th17 cells that produce IL-17, as well as tumor necrosis factor (TNF)- $\alpha$, IL-21, and IL-22 [34•]. An important role for Th17 cells has been demonstrated in murine arthritis models [35]. The exact role of Th17 cells in 
PsA is not clear at this moment, but the Th17-related cytokines IL-17 and IL-23 are expressed in the joints of PsA and RA patients [36]. Clinical studies targeting the Th17 axis are currently under way to establish the validity of this therapeutic approach in patients with PsA. Moreover, blocking the p40 subunit, which is shared by IL-12 and IL-23, leads to amelioration of arthritis in PsA [37].

Lymphoid aggregates of variable size and organization level are not specific for RA but were observed in the synovial biopsies of the majority of 27 PsA patients as well [38]. Clear T-cell/B-cell segregation could be observed, especially in the larger lymphoid aggregates, with many features of lymphoid neogenesis present. Interestingly, a complete response to treatment was associated with a regression of the lymphoid aggregates.

Increased vascularity has been reported in both psoriatic skin lesions and synovial tissue. In the dermis of psoriatic skin, an abundance of dilated and tortuous blood vessels is present [39]. Several authors have reported that PsA synovium is characterized by an increase in macroscopically tortuous blood vessels, and this is more pronounced in-but not exclusive to-PsA than it is in RA synovium [18-20, 40]. Consistent with the vascular abnormalities observed, overexpression of vascular endothelial growth factor, which is involved in angiogenesis, has been reported in immunohistochemical analyses of both psoriatic skin [41] and PsA synovial tissue, together with other vascular markers such as von Willebrand's factor, integrin $\alpha \mathrm{V} \beta 3$, and basic fibroblast growth factor $[15,20,21]$. Upregulation of vascular adhesion molecule 1, intercellular adhesion molecule 1 (ICAM-1), and E-selectin has been reported in PsA synovium [15, 18]. These adhesion molecules are involved in leukocyte adhesion and penetration through the endothelium at sites of inflammation. Interestingly, E-selectin appears to be upregulated in the skin compared with the PsA synovial membrane, and cutaneous lymphocyte-associated antigen is preferentially expressed on leukocytes "homing" to psoriasis lesions, but not to the PsA synovium [42].

A striking feature of PsA synovium is the abundant overexpression of proinflammatory cytokines, including TNF- $\alpha$, IL-1 $\beta$, IL-6, and IL-18 [15]. Another interesting proinflammatory cytokine of the TNF ligand superfamily is TNF-like weak inducer of apoptosis (TWEAK), a pleiotropic cytokine that probably plays a physiologic role in tissue repair via its receptor, Fn14, which is highly induced after injury. The TWEAK/Fn14 pathway promotes local chemokine and cytokine production, resulting in additional infiltration of proinflammatory cells, and facilitates angiogenesis and the proliferation of progenitor cells needed for tissue repair. TWEAK and Fn14 seem to be permanently activated in chronic inflammation, however, and the mechanisms that are beneficial for tissue repair can then contribute to persistent inflammation. TWEAK blockade previously has been ob- served to exert a beneficial effect in an animal model of arthritis. The presence of TWEAK and Fn14 was recently demonstrated in the inflamed synovium of patients with RA and PsA [43]. This raises the possibility that blocking TWEAK/Fn14 signaling could be of therapeutic benefit in inflammatory arthritis.

Another new field of interest is the role of the nervous system in inflammatory arthritis. Considerable evidence indicates that the nervous system can modulate immune responses in several immune-mediated diseases. The cholinergic anti-inflammatory pathway is characterized by neural regulation of systemic inflammation, mediated by the vagus nerve and specific cholinergic stimulation of the nicotinic $\alpha 7$ acetylcholine receptor $(\alpha 7 \mathrm{nAChR})$ on immune cells. Using immunohistochemistry and double immunofluorescence microscopy, the expression of $\alpha 7 \mathrm{nAChR}$-positive cells in synovial tissue from patients with RA and PsA was recently demonstrated. The $\alpha 7 \mathrm{nAChR}$-positive cells were identified as primarily macrophages and fibroblasts in the intimal lining layer and in blood vessels [44•]. This illustrates the potential role of $\alpha 7 \mathrm{nAChR}$ and cholinergic mechanisms controlling arthritis. Another pivotal mediator of neurogenic inflammation is nerve growth factor (NGF). NGF is found in serum, synovial fluid, and cerebrospinal fluid and is highly expressed in inflammatory and degenerative rheumatic diseases. NGF concentrations correlate with the extent of inflammation and clinical disease activity. NGF levels are significantly higher in RA as compared with osteoarthritis [45•]. These findings support the possibility of therapeutic modulation of neurogenic inflammation by intervening with NGF or $\alpha 7 \mathrm{nAChR}$ as a potential anti-inflammatory therapeutic strategy in arthritis.

Taken together, although RA and PsA are clinically separate diseases with different etiologies, the synovial infiltrate in both conditions shows more similarities than differences. On the group level, PsA synovium may have less pronounced intimal lining layer hyperplasia and fewer synovial $\mathrm{T}$ cells compared with RA, but the available studies comparing synovial tissue are relatively small and may be biased by several confounding factors. More importantly, there is overexpression of many proinflammatory cytokines in the synovial tissue of active RA and PsA, including TNF- $\alpha$ and IL-6. Future studies will show whether interventions in newly discovered pathways, such as the proinflammatory cytokine TWEAK, or neurogenic inflammation could also be of therapeutic benefit to patients with inflammatory arthritis.

\section{Effects of Therapy on Psoriatic Arthritis Synovium}

A few studies have been conducted in PsA to evaluate synovial changes after therapy [46-51]. Open-label treatment of 10 PsA patients with methotrexate resulted in a decrease in 
$\mathrm{T}$ cells and macrophages, as well as reduced expression of IL-8, E-selectin, ICAM-1, and matrix metalloproteinase 3 (MMP-3) after 6 to 12 months [46]. In another study, $52 \mathrm{SpA}$ patients with peripheral arthritis were included (16 of whom were classified as PsA [47]) and underwent synovial biopsy at baseline and 12 weeks following different treatment regimens (infliximab, etanercept, sulfasalazine, or no disease-modifying antirheumatic drug). Clinical improvement in this study correlated with a decrease in $\mathrm{CD}_{163}{ }^{+}$ macrophages, polymorphonuclear cells, and MMP-3 expression. Two other smaller studies demonstrated a significant reduction in the expression of the adhesion molecule ICAM1 and the vascular markers von Willebrand's factor and $\alpha \mathrm{V} \beta$ in 11 and 9 PsA patients, respectively, treated with infliximab $[50,51]$. A study on the effects of alefacept revealed a significant decrease in T-cell numbers after 4 weeks of treatment and a significant reduction in both $\mathrm{T}$ cells and macrophages after 12 weeks of treatment in 11 PsA patients [48]. Finally, experimental treatment with IL-10 subcutaneously for 4 weeks in 28 patients resulted in decreased T-cell and macrophage infiltration in the synovium [52].

From these studies, it can be concluded that successful treatment in the long run always leads to deactivation of endothelium, reduced vascularity, and a reduction in infiltrating immune cells. Identical to the approach that we have previously described in RA patients [53], we designed a randomized, placebo-controlled study to determine which early changes in synovial markers are associated with active treatment on the group level [16•]. For this purpose, 24 patients with active PsA were treated with adalimumab or matched placebo at baseline and day 15. Synovial biopsies were taken before and after 4 weeks of treatment. We observed (trends toward) reduced numbers of macrophages and macrophage subsets after active treatment, but a statistically significant effect of treatment was only observed for the reduction in $\mathrm{CD}^{+} \mathrm{T}$ cells and the expression of MMP-13 using analysis of covariance. In addition, clinical improvement was strongly correlated with a decrease in $\mathrm{CD}^{+}{ }^{\mathrm{T}}$ cells, $\mathrm{CD} 4^{+}$cells, and $\mathrm{MRP}^{+}$, as well as MMP-13 and MMP-3. Thus, particularly the reduction of $\mathrm{T}$ cells was correlated with effective therapy and clinical improvement, which was confirmed by another recently published study [54]. This underscores the importance of $\mathrm{T}$ cells in the pathogenesis of PsA [26], consistent with the observation that specific targeting of $\mathrm{T}$ cells may result in clinical benefit in this disease $[31,48,55]$.

\section{Model for Proof-of-Concept Study Design}

The rise in newly discovered drugs and potential therapeutic targets currently under investigation will have consequences for the way potential novel therapies are tested in clinical trials. It will be increasingly difficult to include large numbers of patients with active disease in large, placebo-controlled trials because of the growing number of compounds to be tested and the fact that effective treatment is now available for many patients. Therefore, in an early stage of drug development, it could be useful to perform intensive trials with a small number of patients in which large amounts of data are collected to study the effects of the compound tested. The identification of biomarkers that could be used for prediction of the clinical response to treatment and evaluation of biological effects of potential novel therapies is of the utmost importance for this development. Because synovial inflammation is one of the key manifestations of PsA, we and others have focused on the identification of synovial biomarkers $[16 \bullet, 54]$. Sensitive synovial biomarkers could be used as predictors of clinical effects in small proof-of-principle trials for selection purposes, similar to the approach used in RA [17]. Our study indicates that the reduction in the number of $\mathrm{CD}^{+}$cells and the expression of MMP-13 may be candidate synovial biomarkers to screen for potentially active drugs in small proof-of-concept studies of short duration. As arthroscopic synovial biopsy is not available in all centers, ultrasound-guided biopsy may be another approach [56]. Alternatively, the identification of relevant soluble biomarkers that can be measured in blood would further facilitate the feasibility of small high-density-ofdata clinical trials that are conducted to screen for efficacy. We propose that analysis of serial biopsies may be used as a screening method to test new compounds requiring relatively small numbers of participants. The absence of changes in the synovial tissue after treatment on the group level would suggest that the therapy is probably not effective.

\section{Conclusions}

Most patients with PsA present with peripheral synovitis of the oligoarticular or polyarticular subtype. Therefore, the synovium is, as a primary site of inflammation in this disease, an important tissue to study. Several descriptive immunohistochemical studies of the synovial tissue of patients with RA and PsA show more similarities than differences between the two inflammatory arthropathies, which could point to the activation of common final pathways and similarities in synovial infiltrate in established disease. On the group level, PsA synovium might have less pronounced intimal lining layer hyperplasia, more pronounced vascularity, and fewer synovial T cells compared with RA, but the available studies comparing synovial tissue are relatively small and may be biased by several confounding factors. Effective treatment of patients with PsA in the long run 
will lead to a resolution in synovial inflammation, including deactivation of endothelium, fewer blood vessels, and a reduction in infiltrating immune cells. Two recent studies demonstrated that an early reduction in synovial $\mathrm{T}$ cells after TNF blocking therapy correlated with clinical improvement. We propose a model for early proof-of-concept studies in which sensitive (synovial) biomarkers are used as predictors of clinical effect for selection purposes during early drug development. A reduction in the number of $\mathrm{CD}^{+}$cells and the expression of MMP-13 are interesting candidate synovial biomarkers to screen for potentially active drugs in small proof-of-principle studies of short duration, alongside clinical outcome and imaging measures.

Disclosure No potential conflicts of interest relevant to this article were reported.

Open Access This article is distributed under the terms of the Creative Commons Attribution Noncommercial License which permits any noncommercial use, distribution, and reproduction in any medium, provided the original author(s) and source are credited.

\section{References}

Papers of particular interest, published recently, have been highlighted as:

\section{- Of importance}

1. Kane D, Stafford L, Bresnihan B, Fitzgerald O. A prospective, clinical and radiological study of early psoriatic arthritis: an early synovitis clinic experience. Rheumatol Oxf. 2003;42 (12):1460-8.

2. Rahman P, Nguyen E, Cheung C, Schentag CT, Gladman DD. Comparison of radiological severity in psoriatic arthritis and rheumatoid arthritis. J Rheumatol. 2001;28(5):1041-4.

3. Moll JM, Wright V. Psoriatic arthritis. Semin Arthritis Rheum. 1973;3(1):55-78.

4. Helliwell PS, Taylor WJ. Classification and diagnostic criteria for psoriatic arthritis. Ann Rheum Dis. 2005;64 Suppl 2:ii3-8.

5. Kane D, Stafford L, Bresnihan B, Fitzgerald O. A classification study of clinical subsets in an inception cohort of early psoriatic peripheral arthritis - DIP or not DIP revisited. Rheumatol Oxf. 2003;42(12):1469-76.

6. Taylor W, Gladman D, Helliwell P, Marchesoni A, Mease P, Mielants H. Classification criteria for psoriatic arthritis: development of new criteria from a large international study. Arthritis Rheum. 2006;54(8):2665-73.

7. Helliwell PS, Porter G, Taylor WJ. Polyarticular psoriatic arthritis is more like oligoarticular psoriatic arthritis, than rheumatoid arthritis. Ann Rheum Dis. 2007;66(1):113-7.

8. McGonagle D, Conaghan PG, Emery P. Psoriatic arthritis: a unified concept twenty years on. Arthritis Rheum. 1999;42 (6): 1080-6.

9. McGonagle D, Lories RJ, Tan AL, Benjamin M. The concept of a "synovio-entheseal complex" and its implications for understand- ing joint inflammation and damage in psoriatic arthritis and beyond. Arthritis Rheum. 2007;56(8):2482-91.

10. - McGonagle D, Benjamin M, Tan AL. The pathogenesis of psoriatic arthritis and associated nail disease: not autoimmune after all? Curr Opin Rheumatol. 2009;21(4):340-7. Together with the article by Benjamin and McGonagle [11•], this overview nicely describes recent microanatomic and genetic studies of PsA, psoriasis, and psoriatic-associated nail disease, which leads to an alternative hypothesis for the pathophysiology of psoriatic disease, especially in the case of combined joint and nail disease.

11. - Benjamin M, McGonagle D. The enthesis organ concept and its relevance to the spondyloarthropathies. Adv Exp Med Biol. 2009;649:57-70. This extensive review focuses on the inflammation at tendon or ligament attachment sites and proposes the concept of an enthesis organ. It highlights the fact that stress at an insertion site involves not only the enthesis itself, but neighboring tissues as well, including synovial tissue in bursae and joints. This emphasizes the interdependence between synovial membrane and entheses within enthesis organs. It draws attention to the fact that one component (the enthesis) is prone to microdamage and the other (the synovium) to inflammation.

12. Kraan MC, Haringman JJ, Post WJ, Versendaal J, Breedveld FC, Tak PP. Immunohistological analysis of synovial tissue for differential diagnosis in early arthritis. Rheumatol Oxf. 1999;38 (11):1074-80.

13. Baeten D, Steenbakkers PG, Rijnders AM, Boots AM, Veys EM, De Keyser F. Detection of major histocompatibility complex/ human cartilage gp-39 complexes in rheumatoid arthritis synovitis as a specific and independent histologic marker. Arthritis Rheum. 2004;50(2):444-51.

14. Tak PP, Bresnihan B. The pathogenesis and prevention of joint damage in rheumatoid arthritis: advances from synovial biopsy and tissue analysis. Arthritis Rheum. 2000;43(12):2619-33.

15. van Kuijk AW, Reinders-Blankert P, Smeets TJ, Dijkmans BA, Tak PP. Detailed analysis of the cell infiltrate and the expression of mediators of synovial inflammation and joint destruction in the synovium of patients with psoriatic arthritis: implications for treatment. Ann Rheum Dis. 2006;65(12):1551-7.

16. • van Kuijk AW, Gerlag DM, Vos K, Wolbink G, de Groot M, de Rie MA et al. A prospective, randomised, placebo-controlled study to identify biomarkers associated with active treatment in psoriatic arthritis: effects of adalimumab treatment on synovial tissue. Ann Rheum Dis 2009; 68(8):1303-9. This prospective, placebo-controlled study was conducted to determine which of the changes in synovial tissue correlates best with clinical response associated with effective therapy in PSA. Adalimumab was used as a proven effective therapy, and synovial biopsies were obtained before and after 4 weeks of treatment. Using covariance analysis, it was shown that a significant effect of treatment was observed on reduction of synovial $C D 3^{+} T$ cells and MMP-13, suggesting that these parameters might be used as biomarkers that are sensitive to change after active treatment in small proof-of-concept studies in PsA.

17. Gerlag DM, Tak PP. Novel approaches for the treatment of rheumatoid arthritis: lessons from the evaluation of synovial biomarkers in clinical trials. Best Pract Res Clin Rheumatol. 2008;22(2):311-23.

18. Veale D, Yanni G, Rogers S, Barnes L, Bresnihan B, Fitzgerald O. Reduced synovial membrane macrophage numbers, ELAM-1 expression, and lining layer hyperplasia in psoriatic arthritis as compared with rheumatoid arthritis. Arthritis Rheum. 1993;36 (7):893-900.

19. Reece RJ, Canete JD, Parsons WJ, Emery P, Veale DJ. Distinct vascular patterns of early synovitis in psoriatic, reactive, and rheumatoid arthritis. Arthritis Rheum. 1999;42(7):1481-4. 
20. Fraser A, Fearon U, Reece R, Emery P, Veale DJ. Matrix metalloproteinase 9, apoptosis, and vascular morphology in early arthritis. Arthritis Rheum. 2001;44(9):2024-8.

21. Fearon U, Griosios K, Fraser A, Reece R, Emery P, Jones PF, et al. Angiopoietins, growth factors, and vascular morphology in early arthritis. J Rheumatol. 2003;30(2):260-8.

22. Baeten D, Demetter P, Cuvelier C, Van Den BF, Kruithof E, Van DN, et al. Comparative study of the synovial histology in rheumatoid arthritis, spondyloarthropathy, and osteoarthritis: influence of disease duration and activity. Ann Rheum Dis. 2000;59(12):945-53.

23. Danning CL, Illei GG, Hitchon C, Greer MR, Boumpas DT, McInnes IB. Macrophage-derived cytokine and nuclear factor kappaB p65 expression in synovial membrane and skin of patients with psoriatic arthritis. Arthritis Rheum. 2000;43(6):1244-56.

24. Kruithof E, Baeten D, De RL, Vandooren B, Foell D, Roth J, et al. Synovial histopathology of psoriatic arthritis, both oligo- and polyarticular, resembles spondyloarthropathy more than it does rheumatoid arthritis. Arthritis Res Ther. 2005;7(3):R569-80.

25. Salvador G, Sanmarti R, Garcia-Peiro A, Rodriguez-Cros JR, Munoz-Gomez J, Canete JD. p53 expression in rheumatoid and psoriatic arthritis synovial tissue and association with joint damage. Ann Rheum Dis. 2005;64(2):183-7.

26. Choy E. T cells in psoriatic arthritis. Curr Rheumatol Rep. 2007;9 (6):437-41.

27. Tassiulas I, Duncan SR, Centola M, Theofilopoulos AN, Boumpas DT. Clonal characteristics of $T$ cell infiltrates in skin and synovium of patients with psoriatic arthritis. Hum Immunol. 1999;60(6):479-91.

28. Flytlie HA, Hvid M, Lindgreen E, Kofod-Olsen E, Petersen EL, Jorgensen A, et al. Expression of MDC/CCL22 and its receptor CCR4 in rheumatoid arthritis, psoriatic arthritis and osteoarthritis. Cytokine. 2010;49(1):24-9.

29. Heydendael VM, Spuls PI, Opmeer BC, de Borgie CA, Reitsma JB, Goldschmidt WF, et al. Methotrexate versus cyclosporine in moderate-to-severe chronic plaque psoriasis. N Engl J Med. 2003;349(7):658-65.

30. Salvarani C, Macchioni P, Olivieri I, Marchesoni A, Cutolo M, Ferraccioli G, et al. A comparison of cyclosporine, sulfasalazine, and symptomatic therapy in the treatment of psoriatic arthritis. J Rheumatol. 2001;28(10):2274-82.

31. Mease PJ, Gladman DD, Keystone EC. Alefacept in combination with methotrexate for the treatment of psoriatic arthritis: results of a randomized, double-blind, placebo-controlled study. Arthritis Rheum. 2006;54(5):1638-45.

32. Mease P, Genovese MC, Gladstein G, Kivitz AJ, Ritchlin C, Tak $\mathrm{PP}$, et al. Abatacept in the treatment of patients with psoriatic arthritis: results of a double-blind, randomized, placebo-controlled phase II trial. Arthritis Rheum. 2011;63:939-48.

33. Lee E, Trepicchio WL, Oestreicher JL, Pittman D, Wang F, Chamian F, et al. Increased expression of interleukin 23 p19 and p40 in lesional skin of patients with psoriasis vulgaris. J Exp Med. 2004;199(1):125-30.

34. - Di CA, Di MP, Nestle FO. The IL-23/Th17 axis in the immunopathogenesis of psoriasis. J Invest Dermatol. 2009;129 (6):1339-50. This comprehensive review describes the recently recognized subset of IL-17-producing T-helper cells named Th17 cells. In addition to a review of the development, characterization, and function of human Th17 cells, as well as the crucial role of IL-23 in the context of Th17-cell-dependent chronic inflammation in psoriasis, recent clinical trials targeting the IL-23/Th17 axis in psoriasis are discussed.

35. Lubberts E, Koenders MI, van den Berg WB. The role of T-cell interleukin-17 in conducting destructive arthritis: lessons from animal models. Arthritis Res Ther. 2005;7(1):29-37.

36. Melis L, Vandooren B, Kruithof E, Jacques P, De VM, Mielants $\mathrm{H}$, et al. Systemic levels of IL-23 are strongly associated with disease activity in rheumatoid arthritis but not spondyloarthritis. Ann Rheum Dis. 2010;69(3):618-23.

37. Gottlieb A, Menter A, Mendelsohn A, Shen YK, Li S, Guzzo C, et al. Ustekinumab, a human interleukin 12/23 monoclonal antibody, for psoriatic arthritis: randomised, double-blind, placebo-controlled, crossover trial. Lancet. 2009;373(9664):633-40.

38. Canete JD, Santiago B, Cantaert T, Sanmarti R, Palacin A, Celis $\mathrm{R}$, et al. Ectopic lymphoid neogenesis in psoriatic arthritis. Ann Rheum Dis. 2007;66(6):720-6.

39. Braverman IM, Yen A. Ultrastructure of the capillary loops in the dermal papillae of psoriasis. J Invest Dermatol. 1977;68(1):53-60.

40. Canete JD, Rodriguez JR, Salvador G, Gomez-Centeno A, Munoz-Gomez J, Sanmarti R. Diagnostic usefulness of synovial vascular morphology in chronic arthritis. A systematic survey of 100 cases. Semin Arthritis Rheum. 2003;32(6):378-87.

41. Detmar M, Brown LF, Claffey KP, Yeo KT, Kocher O, Jackman $\mathrm{RW}$, et al. Overexpression of vascular permeability factor/vascular endothelial growth factor and its receptors in psoriasis. J Exp Med. 1994;180(3):1141-6.

42. Pitzalis C, Cauli A, Pipitone N, Smith C, Barker J, Marchesoni A, et al. Cutaneous lymphocyte antigen-positive $\mathrm{T}$ lymphocytes preferentially migrate to the skin but not to the joint in psoriatic arthritis. Arthritis Rheum. 1996;39(1):137-45.

43. van Kuijk AW, Wijbrandts CA, Vinkenoog M, Zheng TS, Reedquist KA, Tak PP. TWEAK and its receptor Fn14 in the synovium of patients with rheumatoid arthritis compared to psoriatic arthritis and its response to tumour necrosis factor blockade. Ann Rheum Dis. 2010;69(1):301-4.

44. - Westman M, Engstrom M, Catrina AI, Lampa J. Cell specific synovial expression of nicotinic alpha 7 acetylcholine receptor in rheumatoid arthritis and psoriatic arthritis. Scand J Immunol. 2009;70(2):136-40. The cholinergic anti-inflammatory pathway is characterized by neural regulation of systemic inflammation, mediated by the vagus nerve and specific cholinergic stimulation of the nicotinic $\alpha 7 n A C h R$ on immune cells. This study demonstrated the expression and localization of $\alpha 7 n A C h R$ in synovial biopsies from patients with $R A$ and PSA, indicating a potential role for $\alpha 7 n A C h R$ in arthritis pathogenesis and implicating specific cholinergic modulation as a potential anti-inflammatory therapeutic strategy in joint inflammation.

45. - Seidel MF, Herguijuela M, Forkert R, Otten U. Nerve growth factor in rheumatic diseases. Semin Arthritis Rheum. 2010;40 (2):109-26. There is considerable evidence to indicate that NGF acts as an important mediator of immune responses. This article reviews the role of NGF in neurogenic inflammation, especially rheumatic diseases, and strategies for potential therapeutic interventions.

46. Kane D, Gogarty M, O’Leary J, Silva I, Bermingham N, Bresnihan B, et al. Reduction of synovial sublining layer inflammation and proinflammatory cytokine expression in psoriatic arthritis treated with methotrexate. Arthritis Rheum. 2004;50 (10):3286-95.

47. Kruithof E, De RL, Vandooren B, De KF, Fitzgerald O, McInnes I, et al. Identification of synovial biomarkers of response to experimental treatment in early-phase clinical trials in spondylarthritis. Arthritis Rheum. 2006;54(6):1795-804.

48. Kraan MC, van Kuijk AW, Dinant HJ, Goedkoop AY, Smeets TJ, de Rie MA, et al. Alefacept treatment in psoriatic arthritis: reduction of the effector $\mathrm{T}$ cell population in peripheral blood and synovial tissue is associated with improvement of clinical signs of arthritis. Arthritis Rheum. 2002;46(10):2776-84.

49. Goedkoop AY, Kraan MC, Teunissen MB, Picavet DI, de Rie MA, Bos JD, et al. Early effects of tumour necrosis factor alpha blockade on skin and synovial tissue in patients with active psoriasis and psoriatic arthritis. Ann Rheum Dis. 2004;63(7):769-73. 
50. Goedkoop AY, Kraan MC, Picavet DI, de Rie MA, Teunissen $\mathrm{MB}$, Bos JD, et al. Deactivation of endothelium and reduction in angiogenesis in psoriatic skin and synovium by low dose infliximab therapy in combination with stable methotrexate therapy: a prospective single-centre study. Arthritis Res Ther. 2004;6(4):R326-34.

51. Canete JD, Pablos JL, Sanmarti R, Mallofre C, Marsal S, Maymo $\mathrm{J}$, et al. Antiangiogenic effects of anti-tumor necrosis factor alpha therapy with infliximab in psoriatic arthritis. Arthritis Rheum. 2004;50(5):1636-41.

52. McInnes IB, Illei GG, Danning CL, Yarboro $\mathrm{CH}$, Crane $\mathrm{M}$, Kuroiwa $\mathrm{T}$, et al. IL-10 improves skin disease and modulates endothelial activation and leukocyte effector function in patients with psoriatic arthritis. J Immunol. 2001;167(7):4075-82.

53. Gerlag DM, Haringman JJ, Smeets TJ, Zwinderman AH, Kraan MC, Laud PJ, et al. Effects of oral prednisolone on biomarkers in synovial tissue and clinical improvement in rheumatoid arthritis. Arthritis Rheum. 2004;50(12):3783-91.

54. Pontifex EK, Gerlag DM, Gogarty M, Vinkenoog M, Gibbs A, Burgman I, et al. Change in CD3 positive T-cell expression in psoriatic arthritis synovium correlates with change in DAS28 and magnetic resonance imaging synovitis scores following initiation of biologic therapy - a single centre, open-label study. Arthritis Res Ther. 2011;13(1):R7.

55. Canete JD, Celis R, Hernandez V, Pablos JL, Sanmarti R. Synovial immunopathological changes associated with successful abatacept therapy in a case of severe refractory psoriatic arthritis. Ann Rheum Dis. 2010;69(5):935-6.

56. van de Sande MG, Gerlag DM, Lodde BM, van Baarsen LG, Alivernini S, Codullo V, et al. Evaluating antirheumatic treatments using synovial biopsy: a recommendation for standardisation to be used in clinical trials. Ann Rheum Dis. 2011;70:423-7. 